Editorial

\title{
Review of the New Zealand's COVID-19 Elimination Plan and the Mental Health Fall out on Vulnerable Groups
}

\author{
Dolapo Babalola ${ }^{1 *}$
}

${ }^{1}$ College of Medicine, University of Ibadan, Ibadan, NIGERIA

*Corresponding Author: dolapo74@gmail.com

Citation: Babalola, D. (2020). Review of the New Zealand's COVID-19 Elimination Plan and the Mental Health Fall out on Vulnerable Groups. European Journal of Environment and Public Health, 4(2), em0058. https://doi.org/10.29333/ejeph/8456

\section{ARTICLE INFO}

Received: 16 Jun. 2020

Accepted: 20 Jul. 2020

\begin{abstract}
Around the time when several countries battle with COVID-19 pandemic, the New Zealand implemented an elimination strategy- a headway that successfully eliminated the novel SARS-CoV-2 from Aotearoa/ New Zealand. A review of the elimination plan shows an extended and strict restrictions on social contact that could cause mental health fall out particularly among the vulnerable groups such as the aged, prisoners, and people with preexisting mental health issues. For a proactive action against these after-lockdown possibilities, surveillance of the risk factors among the vulnerable groups, deliberate interventional psychiatric and psychological care, and investment in mental health personnel training should be first point of action. Hence, this paper aims at drawing attention to these needed response.
\end{abstract}

Keywords: COVID-19, New Zealand, public health, mental health, pandemic

\section{INTRODUCTION}

As at 10 June 2020 the COVID-19 infection caused by the novel severe acute respiratory syndrome coronavirus 2 has infected $7,145,539$ people in 6 continental regions across the globe (WHO COVID-19 Dashboard). This among other reasons, the infection was declared a pandemic by the World Health Organization on the 11 March 2020. (WHO Timeline - COVID19). A recent review by Adesanya et al shows that the astronomic spread of the infection is caused largely by the unavailability of a suitable therapeutic agent against the virus, and clinical trial of potential vaccine candidates have not yielded promising result (Adesanya et al., 2020). While top players in public health leadership grapples with the scourge, the Prime Minister of New Zealand announced on the 8 June 2020 that the country has successfully flattened the Corona Virus Disease 2019 curve. (New Zealand lifts all Covid restrictions, - BBC News) As reported by the World Health Organization COVID-19 progress database, the country reported her first index case on the 28 February 2020, and by 22 May 2020 there were total 1,154 reported COVID-19 cases and 22 deaths before the curve was eventually flattened(New Zealand: WHO COVID-19 Dashboard). The successful elimination of COVID-19 must have possibly placed the country in higher stratospheric level among league of public health leaders, and also possibly reinforced the confidence of the citizens in the Ministry of Health of Aotearoa/ New Zealand.

Elimination of COVID-19 from Aotearoa/New Zealand is a result of a grand emergency plan. The blue print was created with equity, wellbeing and weighting (what might potentially go wrong) as it core principles, with special consideration of minority groups such as the Maori, pacific people, and consideration of isolated groups (COVID-19: Elimination strategy for Aotearoa New Zealand). The elimination strategy was straight and well defined- reducing new cases in a defined geographical area, in this case Aotearoa/New Zealand, to zero (or a very low defined target rate) and also to prevent the emergence of new transmission chains originating from cases that arrive from outside the country. The public health system of New Zealand greatly leveraged on the control of transmissibility as a major influence in shorting down the basic reproduction number ( $\mathrm{R}$ value) to 1 (Ministry of Health, 2020). Reduction of contact rate was as well used in contributing to reducing $\mathrm{R}$ value to 1 at the least and less than 1 at the best. Understandably, the reduction of infectivity duration contributed least to the elimination success due to unavailability of effective antiviral therapeutic agent. Another major highlight of the public health elimination plan against SARS-CoV-2 is the consideration of possible indicators of failure along the line which were categorized according to (1) complete failure if the health care system is overwhelmed by new cases of COVID-19 considering test capacities, treatment and personal protective equipment, and new inequity in 
COVID-19 and non-COVID-19 health care (2) partial failure if there is increased positive test in a particular region especially the isolated areas and high-risk region such as prisons despite surveillance (3) breach of border measures if there are emergent COVID-19 cases of international origin even after quarantine (Ministry of Health, Overview of Elimination plan 2020). All the strategy employed was backed up by the new COVID-19 Public Health Response Act 2020; these show that the strategy went through the due process, a core part of rule of law, despite the quick need of implementation (Act, 2020).

The time thread for the security alert measure implemented ranged from Alert level 4- lockdown on 25 March 2020 , when the daily active cases was all time high at 47 daily new cases and 189 cumulative cases to Alert level 2 on 13 May 2020, when the number of new active cases was stamped down to zero. (NZ Alert system overview ) Apparently, the three consecutive Alert levels contributed to the success of flattening the curve; New Zealand recorded zero new cases on 23 May 2020 before 8 June 2020 that ended the continuance of Alert level 2-reduce, switching to Alert level 1-prepare (New Zealand: WHO COVID-19 Dashboard). The 75 days sequent lockdown before Alert Level 1, however, should be of public health concern. The strict restriction measures especially for the first 33 days of tough lockdown may trigger mental distress risk factors among subjected vulnerable groups. Hence, the aim of this paper. This editorial aims to review the elimination plan, shine light on the possible mental health risk fall out among vulnerable groups, and iterate the need for response against future mental health escalation, and recommend response plan.

\section{DISCUSSION}

The elimination strategy and the order of implementing the alert levels at each stage of the fight to stamp down the number of COVID-19 new cases in Aotearoa /New Zealand is characterized by 75 days of consecutive restriction and social lockdown. More reason the strategy was successful as reduction of social interaction is needed for a disease that is transmitted through contact with respiratory droplet, direct contact with infected person or by direct contact with contaminated surfaces or object as the case of COVID-19 (WHO, 2020). The aftermath of the strict lockdown, particularly during the first 33 days of implementing Alert level 4- lockdown, could possibly be a surge in poor mental health risk factors particularly among the vulnerable groupsaged, the incarcerated, pre-existing psychiatric patient of New Zealand citizens (Holmes et al., 2020). While there is no available evidence to support the direct pathological influence of the SARS-CoV-2 infection on the neurological pathway that could harm mental health, reduction of human interaction, stay at home order for a very long stretch of time has substantial short term and long term impact on the mental health of said group. As highlighted by Holmes et al, the fall out of mental illness such as anxiety, depression, alcoholism, post traumatic shock, suicide ideation and action, to mention some, is inevitable during uncertain time of this kind (Holmes et al., 2020).
As the aged $-75 \mathrm{~s}$ and above seem to be the quite vulnerable groups to COVID-19 caused death (Li et al., 2020), they are advice strongly to stay home and avoid social interaction, just like all other citizens are encouraged to. It is expected that the period of lockdown should be an opportunity to rest, but contrary is the case; many aged are prone to loneliness, and depression which are hitherto reduced by social interaction such as in person social network groups (Routasalo et al., 2006). Moreover, there have been cases of domestic violence plausibly caused by frustration due to extreme lockdown, financial incapacitation in low-income homes, to mention some (Bradbury-Jones and Isham, 2020); then one can posit that such violence could be meted on vulnerable aged citizens in their domestic abode (Han and Mosqueda, 2020). All these have been shown to be exacerbated by prolonged lockdown as social network was cut short, and as inadequate or no or no psychiatric intervention was provided. In addition, aged COVID-19 patients have poor survival chance due to preexisting health conditions (Li et al., 2020), such awareness may trigger anxiety among the aged.

The narrative of COVID-19 infection in correctional centre are quite different from what can be obtained outside; and it has been reported to be worse (Montoya-Barthelemy et al., 2020). It is a difficult position for inmates at a time like this when the needed method of curbing COVID-19 infection is through lockdown, because of (1) perpetual influx and efflux of inmates as well as correctional facility staffs, (2) difficulty of social distancing as inmates are confined to their cells, required to share water, sanitation and hygiene facilities, and also barred from owning personal protective equipment, mask and alcohol-based hand sanitizer, (3) high severity of infection for long-term older inmates with pre-existing health problem, and (4) infected staffs are relieved of their duty resulting into short-staffed that can cause the need for prolonged confinement into cells. Thus, correctional centres were lockdowned and visitations were banned (Rubin, 2020). This is, indeed, true for prisoners of Auckland Region Women's Corrections Facility in Wiri in New Zealand that was reported to have been locked up for up to 29 hours on some days during the 33 days consecutive lockdown of Alert level-4 (Covid-19: Prisoners Confinement); and these mal-conditions subjected on prisoners could cause a mental health crisis that have been emphasised earlier on in this paper. And it can be more difficult for inmates with pre-existing mental illness such as drug use, depression, and anxiety; self harm and hike of violence among in mates (that can be likened to domestic violence among free citizens) is also a possibility.

Furthermore, to buttress the need for action against mental health fall out, the New Zealand government has recorded a hitherto alarming rate of mental health distress indicators among her citizens before the pandemic. For instance, it has been reported in New Zealand Health survey that $15 \%$ of adult were current smokers, $4 \%$ of young citizens of 15-17 years old have used tobacco products, and adults in the most deprived areas were 1.3 times as likely to be hazardous drinkers as adults in the least deprived areas, after adjusting for age, gender and ethnic differences (2017/18 New Zealand Health Survey). A recent study has also shown that one-third (35\%) of prisoners in New Zealand experienced suicidal ideation in their lifetime, and one-fifth (19\%) had even 
attempted suicide (Favril et al., 2020). A recent report by Buschmann et al of autopsies of 10 suicide cases shows that all suffered from pre-existing mental issues such as depression and hypochonderiacal delusion with fear of COVID-19, and none was infected with SARS-CoV-2 prior to suicide (Buschmann et al., 2020). When citizens are restricted to their homes, with inadequate quality social and human contact and bonding, there is a possibility of binge drinking, excessive smoking and substance use, spike in domestic violence - all capable of inciting suicide ideation and suicide action especially among the vulnerable groups - aged, prisoners, isolated groups and on (Farhoudian et al., 2020). All these preexisting mental health risk factors can be exacerbated due to the restriction caused by the needed long ranged lock down on New Zealand's most vulnerable groups.

The psychiatric intervention to tend to this mental health fallout should be two pronged- in-pandemic action and postpandemic action. The period after Alert level 1-Prepare was in action from 8 June 2020, with relatively relieved burden on the health care system of the country, provides a golden window of opportunity for the Ministry of Health. A framework to identify vulnerable groups that might have been affected by mental distress due to the lockdown should be designed; this should be humane enough to avoid re-trauma (Notice on the issuance of guiding principles of emergency psychological crisis intervention for pneumonia outbreaks of new coronavirus infection). Previous psychiatric patient, particularly among the vulnerable groups, whose treatment was halted due to lockdown should be encouraged to resume treatment without fear of been isolated or quarantined (especially those with anxiety disorders). The use of telemedicine may not be suitable for people such as the aged; they may not be able to navigate through the interface of such technology, and some may not have financial cap involved in procuring the devices and the source of internet to access the from-home care via such route as the pandemic has reduced income, and may be inadequate for such group to say the least. Thus, special attention must be given to them through home visit for psychiatric or psychological regimen, emotional support; phone call for follow up; and they should be recommended to join social support network (Ornell et al., 2020). As a contingency plan, there is need for proactive effort in preparing for mental health crisis post-COVID-19 as New Zealand may be fighting mental health crisis as the aftermath of strict lockdown measure on citizens, and the psychosocial effect of the pandemic itself. More so, the mental trauma caused by this pandemic is quite different in perspective and approach by mental health professionals in comparison to other mental health-crisis-inducing occurrences such as natural disaster (Fiorillo et al., 2020). Hence, the need for more pandemic-peculiarly trained mental health staffspsychiatrists, clinical psychologists, liaison psychiatrist (to monitor psychiatric patients who has once recovered from COVID-19), is important in preparation for postCOVID-19 mental health crisis.

Admitted, the pandemic met the whole world halfprepared as giants in the public health system are still battling with the scourge of COVID-19, and New Zealand was no exception. This paper, then, does not have any intention of downplaying the brilliant effort by the New Zealand Ministry of Health in snuffing out SARS-CoV-2 from the country, rather put the possible mental health fallout among the vulnerable groups into limelight. The country applied the rule of law which can be quoted as the "the rule of law, not the rule of men" by ensuring the elimination plan and the timeline of the Alert Level system went through due process by noting the possible equity stress in the elimination stages; and the content of this paper is not casting a stone to the government in the actual sense of it. This paper rather implores the government to take cue from the proposed interventions in here, in planning a robust and inclusive mental health care post-lockdown and even post-COVID-19 targeted at the vulnerable groups. In addition, it is very important that sampling and adoption of New Zealand's elimination plan by other public health care system should be done with consciousness of possible mental health issues among the highly vulnerable groups.

\section{CONCLUSION}

COVID-19 pandemic has affected virtually every part of the world. And the pandemic has shown us all how weak and unsophisticated our public health emergency system we have on ground. In the midst of all these, the New Zealand public health system have given all us a sense of hope- elimination of the virus is achievable. Although the elimination plan and the newly enacted public health emergency policy are rule of law processed and equity conscious, the mental health impact on vulnerable groups should be given attention by the New Zealand Ministry of Health, and other public health systems willing to adopt or sample New Zealand's COVID-19 elimination plan. Surveillance of the risk factors among the vulnerable groups, deliberate interventional psychiatric and psychological care, and investment in mental health personnel training can be a first point of action. Long period lockdown is really a thing; we must proactively attend to the mental health issue that may surface post-lockdown and post-COVID-19. Otherwise, we should await mental health crisis after the pandemic which in itself can be another pandemic.

\section{RECOMMENDATION FOR FURTHER RESEARCH}

The nature of the mental health fall out, especially as it concerns vulnerable groups, of the kind of a typical pandemiccaused may be quite different from the one from other natural disasters such as earthquake. In light of this, it is recommended that an extensive and progressive research be done on the peculiarities of mental health crisis from a pandemic such as COVID-19 pandemic to the end of having a scholarly accessed policy-making tool for a response. In addition, further research should be done on the safe scaling of the New Zealand elimination plan to other public health system to the end of SARS-CoV-2 infection eradication. 


\section{REFERENCES}

Act, P. (2020). COVID-19 Public Health Response Act 2020 128.

Adesanya, O. A., Adewale, B. A., Ebengho, I. G., Okwunze, K. F., Ebengho, J. O., Fakorede, O. A., Olugbamigbe, I. D. and Igwe, H. A. (2020). Current Knowledge on the Pathogenesis of and Therapeutic Options against SARS-CoV-2: An Extensive Review of the Available Evidence. Int. J. Pathog. Res. 4, 16-36. https://doi.org/10.9734/ijpr/2020/v4i230108

Alert system overview | Unite for Recovery [WWW Document], d. g. https://uniteforrecovery.govt.nz/covid-19/covid-19alert-system/alert-system-overview/ (Accessed: 15 June 2020).

Annual Update of Key Results 2017/18: New Zealand Health Survey | Ministry of Health NZ [WWW Document], d. g. https://www.health.govt.nz/publication/annual-updatekey-results-2017-18-new-zealand-health-survey (Accessed: 12 June 2020).

Bradbury-Jones, C. and Isham, L. (2020). The pandemic paradox: The consequences of COVID-19 on domestic violence. J. Clin. Nurs. 29, 2047-2049. https://doi.org/ 10.1111/jocn.15296

Buschmann, C. and Tsokos, M. (2020). Corona-associated suicide - Observations made in the autopsy room. Leg. Med. https://doi.org/10.1016/j.legalmed.2020.101723

COVID-19: Elimination strategy for Aotearoa New Zealand | Ministry of Health NZ [WWW Document], d. g. https://www.health.govt.nz/our-work/diseases-andconditions/covid-19-novel-coronavirus/covid-19-currentsituation/covid-19-elimination-strategy-aotearoa-newzealand (Accessed: 15 June 2020).

Covid-19: Prisoners confined to cells for up to 29 hours, diary shows | RNZ News [WWW Document], d. g. https://www.rnz.co.nz/news/national/415563/covid-19prisoners-confined-to-cells-for-up-to-29-hours-diaryshows (Accessed: 20 July 2020).

Farhoudian, A., Baldacchino, A., Clark, N., Gerra, G., Ekhtiari, H., Dom, G., ... and Mohammad Razaghi, E. (2020). COVID19 and Substance Use Disorders as Brain Diseases: Recommendations to a Comprehensive Healthcare Response. An International Society of Addiction Medicine (ISAM) Practice and Policy Interest Group Position Paper. Basic Clin. Neurosci. J., 98, 129-146. https://doi.org/10.32598/bcn.11.covid19.1

Favril, L., Indig, D., Gear, C. and Wilhelm, K. (2020). Mental disorders and risk of suicide attempt in prisoners. Soc. Psychiatry Psychiatr. Epidemiol. https://doi.org/10.1007/ s00127-020-01851-7

Fiorillo, A. and Gorwood, P. (2020). The consequences of the COVID-19 pandemic on mental health and implications for clinical practice. https://doi.org/10.1192/j.eurpsy.2020.35
Han, S. D. and Mosqueda, L. (2020). Elder Abuse in the COVID19 Era. J. Am. Geriatr. Soc., 2019, 1-2. https://doi.org/10.1111/jgs.16496

Holmes, E. A., O’Connor, R. C., Perry, V. H., Tracey, I., Wessely, S., Arseneault, L., ... and Bullmore, E. (2020). Multidisciplinary research priorities for the COVID-19 pandemic: a call for action for mental health science. The Lancet Psychiatry, 547-560. https://doi.org/10.1016/S22150366(20)30168-1

Li, X., Xu, S., Yu, M., Wang, K., Tao, Y., Zhou, Y., ... and Zhao, J. (2020). Risk factors for severity and mortality in adult COVID-19 inpatients in Wuhan. J. Allergy Clin. Immunol. https://doi.org/10.1016/j.jaci.2020.04.006

Ministry of Health (2020). Aotearoa / New Zealand's COVID -19 elimination strategy: an overview.

Montoya-Barthelemy, A. G., Lee, C. D., Cundiff, D. R. and Smith, E. B. (2020). COVID-19 and the Correctional Environment: The American Prison as a Focal Point for Public Health. Am. J. Prev. Med., 58, 888-891. https://doi.org/10.1016/j.amepre.2020.04.001

New Zealand lifts all Covid restrictions, declaring the nation virus-free - BBC News [WWW Document], d. g. https://www.bbc.com/news/world-asia-52961539 (Accessed: 16 June 2020).

New Zealand: WHO Coronavirus Disease (COVID-19) Dashboard [WWW Document], d. g. https://covid19. who.int/region/wpro/country/nz (Accessed: 15 June 2020).

Notice on the issuance of guiding principles of emergency psychological crisis intervention for pneumonia outbreaks of new coronavirus infection [WWW Document], d. g. http:/www.nhc.gov.cn/xcs/zhengcwj/202001/6adc08b966 594253b2b791be5c3b9467.shtml (Accessed: 14 June 2020).

Ornell, F., Schuch, J. B., Sordi, A. O. and Kessler, F. H. P. (2020). «Pandemic fear» and COVID-19: mental health burden and strategies. Rev. Bras. Psiquiatr., 42, 232-235. https://doi.org/10.1590/1516-4446-2020-0008

Routasalo, P. E., Savikko, N., Tilvis, R. S., Strandberg, T. E. and Pitkälä, K. H. (2006). Social Contacts and Their Relationship to Loneliness among Aged People - A Population-Based Study. Gerontology, 52, 181-187. https://doi.org/10.1159/000091828

Rubin, R. (2020). The Challenge of Preventing COVID-19 Spread in Correctional Facilities. JAMA - J. Am. Med. Assoc. https://doi.org/10.1001/jama.2020.5427

WHO (2020). WHO siterep 73. World Heal. Organ. 2019, 2633. https://doi.org/10.1001/jama.2020.2633

WHO Coronavirus Disease (COVID-19) Dashboard [WWW Document], d. g. https://covid19.who.int/ (Accessed: 15 June 2020).

WHO Timeline - COVID-19 [WWW Document], d. g. https://www.who.int/news-room/detail/27-04-2020-whotimeline---covid-19 (Accessed: 15 June 2020). 